\title{
Benign hereditary chorea, not only chorea: a family case presentation
}

\author{
Jeanette Koht ${ }^{*}$, Sven Olav Løstegaard ${ }^{2}$, Iselin Wedding ${ }^{2,3}$, Marie Vidailhet ${ }^{4}$, Malek Louha ${ }^{5}$ and \\ Chantal ME Tallaksen ${ }^{2,3}$
}

\begin{abstract}
Background: Benign hereditary chorea is a rare disorder which is characterized by early onset, non-progressive choreic movement disturbance, with other hyperkinetic movements and unsteadiness also commonly seen. Hypothyroidism and lung disease are frequent additional features. The disorder is caused by mutations of the NKX2-1 gene on chromosome 14.

Case presentation: A Norwegian four-generation family with eight affected was identified. All family members had an early onset movement disorder, starting before one year of age with motor delay and chorea. Learning difficulties were commonly reported from early school years. The family presented with choreic movements at rest, but other movements were seen; myoclonus, dystonia, ataxia, stuttering and tics-like movements. All patients reported unsteadiness and ataxic gait was observed in two patients. Videos are provided in the supplementary material. Most affected family members had asthma and a subclinical or clinical hypothyroidism. Sequencing revealed a mutation in the NKX2-1 gene in all eight affected family members.

Conclusions: This is the first Norwegian family with benign hereditary chorea due to a mutation in the NKX2-1 gene, c.671 T> G (p.Leu224Arg). This family demonstrates well the wide phenotype, including dystonia, myoclonus and ataxia.
\end{abstract}

Keywords: BHC, Benign hereditary chorea, Ataxia, Dystonia, Myoclonus, NKX2-1 gene

\section{Background}

Benign hereditary chorea (BHC, MIM 118700) is an autosomal dominant movement disorder, characterized by early onset choreic movements and often hypotonia and delayed motor development [1-5]. In addition, other hyperkinetic movements may be present in up to $50 \%$ of patients [5-10]. The hyperkinetic movements are typically aggravated by stress and disappear during sleep. BHC patients show minimal or no disease progression, and progressive dementia is not observed [11, 12]. Typically, an MRI of the brain shows no structural changes. The severity of symptoms varies widely, even in families with the same disease-causing mutation $[5,6,13,14]$. Thirty percent of the patients appear to be sporadic in large cohorts due to reduced penetrance and de-novo deletions $[5,6]$.

The epidemiology of $\mathrm{BHC}$ is uncertain as the disease is rare and symptoms can be subtle. A prevalence estimate from

\footnotetext{
*Correspondence: jeanette.koht@medisin.uio.no

'Department of Neurology, Drammen Hospital, Vestre Viken Health Trust,

Drammen, Norway

Full list of author information is available at the end of the article
}

Wales was 1 per 500 000, but this was done prior to genetic testing and the prevalence thus remains uncertain [4].

$\mathrm{BHC}$ is most often caused by mutations in the NKX2-1 gene on chromosome 14 [15-17], but up to $50 \%$ of the families initially given a clinical BHC diagnosis tested negative for mutations in the NKX2-1 gene, however mutations in other genes may be associated with a similar phenotype, Table $1[6,7,9,18,19]$. As of today, sixty-one mutations have been described in the NKX2-1 gene [6]. Genotype-phenotype correlations have not been found, but a milder phenotype is most often reported in patients with a missense mutation affecting the terminal regions of the protein compared to those with large deletions of the gene $[1,2,5,6,13,15-17,20-22]$. The gene encodes a homeodomain-containing transcription factor, TITF-1 (thyroid transcription factor-1), which is essential for the organogenesis of lung, thyroid and basal ganglia. The mutations are presumed to be disease causing due to haploinsufficiency [1,2]. Mutations in the NKX2-1 gene can also be associated with hypothyroidism and pulmonary disease as part of the "brain-lung-thyroid syndrome"[23]. 
Table 1 Differential diagnoses for benign hereditary chorea

\begin{tabular}{|c|c|c|c|}
\hline Diagnose $^{a}$ & Gene & Genetic clues $^{\mathrm{e}}$ & Main clinical features \\
\hline Benign hereditary chorea (BHC) & NKX2-1 & $A D$, early onset & Hypotonia, chorea, lung and thyroid symptoms \\
\hline Myoclonus dystonia (DYT11) & SGCE & $A D$, maternal imprinting & Myoclonus of short duration (<150 ms), dystonia \\
\hline BHC like disorder & $A D C Y 5$ & $A D$ & Paroxysmal choreic/dystonic movements, facial myokymia \\
\hline Huntington's disease ${ }^{b}$ & HTT & $A D$, anticipation & Chorea, athetosis, worsen over time, psychiatric symptoms and dementia \\
\hline $\begin{array}{l}\text { Huntington's disease - like } \\
\text { disorder } 1-4^{c}\end{array}$ & PRNP, JPH3, TBP & $A D / A R$ & Chorea, athetosis, worsen over time, psychiatric symptoms and dementia \\
\hline $\begin{array}{l}\text { Other Huntington's - like } \\
\text { disorders }\end{array}$ & RNF216 & $A R$ & $\begin{array}{l}\text { Cerebellar ataxia, behavioral problems, dementia, white matter lesions, } \\
\text { hypogonadotropic hypogonadism, in some families chorea and athetosis }\end{array}$ \\
\hline Ataxia telangiectasia & ATM & $A R$ & Oculomotor apraxia, telangiectasia, dystonia \\
\hline $\begin{array}{l}\text { AOA1 (Ataxia with } \\
\text { oculomotor apraxia 1) }\end{array}$ & APTX & AR & $\begin{array}{l}\text { Early-onset cerebellar signs, sensory neuropathy, cognitive } \\
\text { decline, and oculomotor deficits }\end{array}$ \\
\hline Friedreich ataxia & FXN & $A R$ & $\begin{array}{l}\text { Sensory disturbances, spaticity, hyporeflexia, rare presentations } \\
\text { with chorea and myoclonus }\end{array}$ \\
\hline $\begin{array}{l}\text { Hereditary ataxias } \\
\text { (SCA } 1,2,3,6,7,17, \mathrm{DRPLA})\end{array}$ & $\begin{array}{l}\text { ATXN1-3, CACNA1A, } \\
\text { ATXN17, TBN, ATN1 }\end{array}$ & $A D$ & Progressive ataxia, cerebellar (and brainstem) atrophy \\
\hline $\begin{array}{l}\text { Glucose transporter } \\
\text { type } 1 \text { deficiency }\end{array}$ & $S\lfloor C 2 A 1$ & $A D$ & $\begin{array}{l}\text { Chorea and often mental retardation associated with a } \\
\text { combination of paroxysmal ataxia, dystonia and/or epilepsy }\end{array}$ \\
\hline $\begin{array}{l}\text { Neurodegeneration with brain } \\
\text { iron accumulation (NBIA) }\end{array}$ & PANK2 & AR/X-linked/AD & Typical MRI findings, dystonia, progression, cognitive decline \\
\hline
\end{tabular}

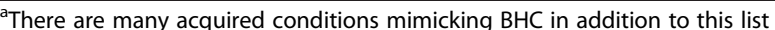

bIn Huntington's disease the juvenile forms often present with dystonia or parkinsonism

'Huntington disease like (HDL) 1-4; unknown gene in HDL3 (questioned entity), HDL4 the same as SCA17. HDL1 also known as inherited prion disease

${ }^{\mathrm{d}}$ Mutations in ten genes can cause NBIA. Mutations in PANK2 is the most common

eMany of these disorders appear sporadic due to reduced penetrance/age-dependent penetrance, variable expressivity and de-novo mutations

The clinical spectrum in patients with mutations in the NKX2-1 gene varies from the complete triad of brain-lungthyroid syndrome (up to $\sim 50 \%$ of the patients), to brain and thyroid disease $(\sim 30 \%)$, or isolated BHC ( 20\%) which is the mildest expression of the syndrome [5], Fig. 1.

No curative treatment for this disorder is currently available, but there is one report of improvement in the hyperkinetic movements from tetrabenazine in a few patients who tried the medication [5]. In addition case articles have reported effect of levodopa $[5,20]$ and methylphenidate or haloperidol [24] in a few other subjects.

A large BHC cohort was described in 2012 [5], including this Norwegian family. The objective of this study is to provide a detailed description of the clinical data, medication response, neuropsychological features and videos from this first Norwegian BHC family.

\section{Case presentation \\ Methods and patients}

During an ongoing study on movement disorders and hereditary ataxias in Norway [25], this four-generation family with eight affected subjects was referred to the department with possible hereditary ataxia, Fig. 2.

Videos were recorded from the examinations for all affected subjects and reviewed by experienced clinicians. The Scale for the Assessment and Rating of Ataxia (SARA-scale) was used to rate ataxia-related symptoms on a scale from 0 (no ataxia) to 40 (severe ataxia) [26].
Brain MRI scanning, mini-mental state test (MMS) and neuropsychological tests were performed in four available affected family members. Due to different ages, different test panels were used. WISC-IV $(<18$ years) and WASI ( $>18$ years) were used for assessment of the Intelligence Quotient (IQ). Verbal Fluency Test, Stroop test and California Verbal Learning Test (CVLT) were performed to assess verbal executive function, executive functions with inhibition, selective attention, and verbal learning and memory. Paced Auditory Serial Addition Test (PASAT) was used to assess attention and working memory [27-29]. Due to geographical restrictions it was not possible to test all family members.

Blood samples were collected from all affected and unaffected family members. DNA was extracted from blood lymphocytes and sequenced using standard techniques. The sequence data have been described in an earlier publication [5].

Written informed consent was obtained from all included family members in accordance with the ethical agreement $n^{\circ} 129 / 04011$ of the Regional Ethical Committee in Norway.

\section{Clinical data}

Age of onset was during the first year of life in all subjects and hyperkinetic movements were the first reported symptoms in all. All affected subjects had delayed motor skills, but $4 / 8$ reached the walking milestone 


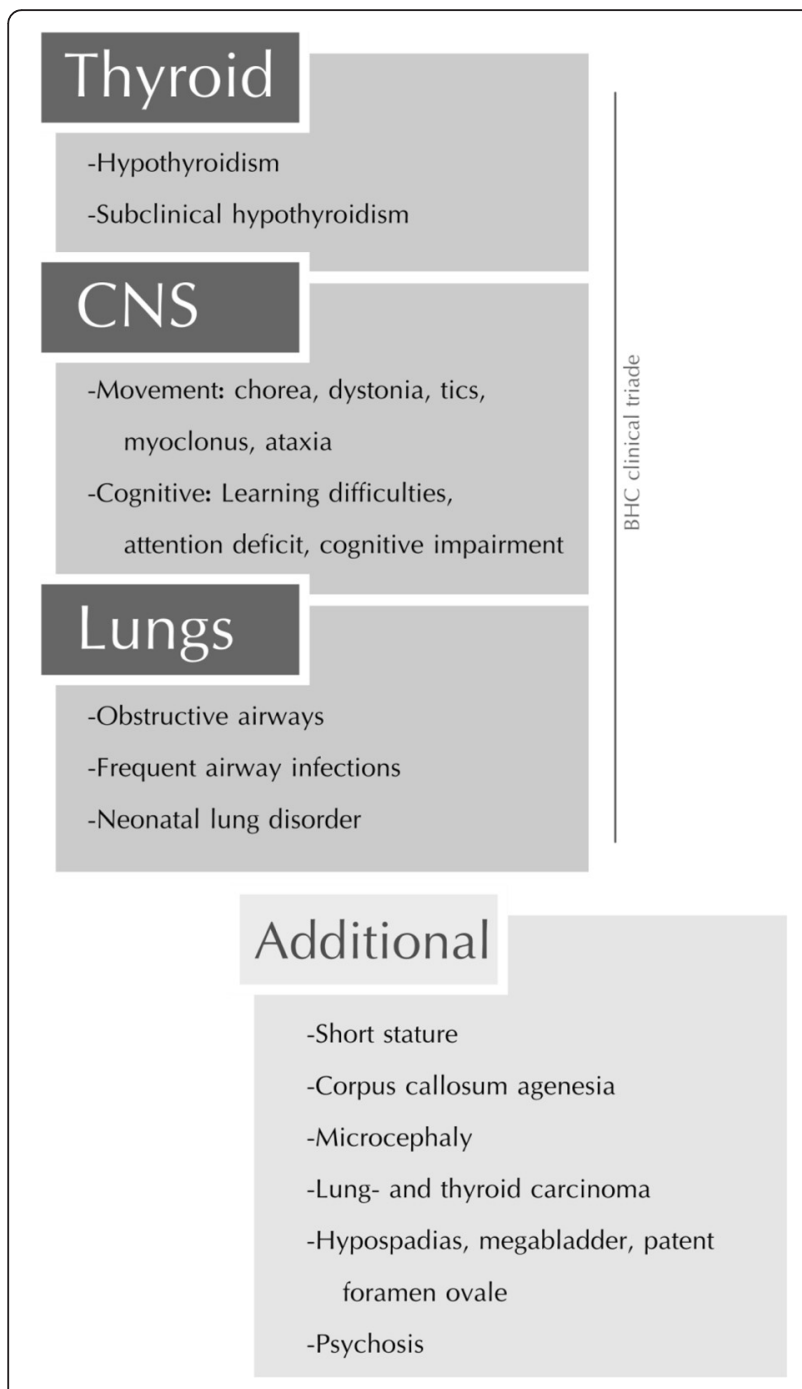

Fig. 1 The clinical spectrum of Benign Hereditary Chorea

within normal range. The movement disorder was reported to be stable, but observed to be more prominent in the youngest generation. All patients reported increased symptoms with stress and two reported some relief in hyperkinetic movements with ethanol consumption. Learning difficulties in early school age was reported in $7 / 8$. Only one of the patients had an academic education. Clinical data are given in Table 2 .

The mean age at the time of examination was 36 years with an average of 33.5 years (range 7-63 years). All subjects had involuntary movements with chorea at the time of examination. Chorea was the most prominent hyperkinetic movement in the three youngest, Additional file 1: Video 1. The older generations exhibited myoclonus (one subject), a mixture of dystonia and chorea (three subjects), Additional file 2: Video 2, and tics, stuttering and dystonia (one subject). All subjects were unsteady and unable to walk ten steps in tandem and two subjects had mild gait ataxia, Additional file 3: Video 3. Saccadic pursuit was consistently observed in all when tested for slow pursuit. Hanging reflexes or increased reflexes were seen in $7 / 8$, Additional file 2: Video 2. Archimedes spiral drawing was inaccurate in all the affected subjects, illustrated by subject IV-2, Fig. 3.

No changes in symptoms were observed in the index patient and the youngest generation at two years follows up time.

Brain MRI's were normal in the four scanned subjects.

No short stature, microcephaly, epilepsy, pulmonary carcinoma or psychiatric disorders were reported or observed in the family.

Levodopa failed to improve the involuntary movements in II:7 and III:6 (1.5-3 mg/kg/day). Clonazepam (0.5 mg/ day) relieved the hyperkinetic symptoms in III:7 to some degree, but III:6 observed only side-effects (dizziness and fatigue). Tetrabenazine was tested in increasing doses in IV:2 and IV:3 (up to $0.35 \mathrm{mg} / \mathrm{kg} /$ day). Side-effects appeared after a few days and the medication was discontinued after one week with nocturnal bed-wetting for IV:2 and depressive symptoms in IV:3. Topiramate was tried in two subjects with $\mathrm{BMI}>30$. They reported some reduction in involuntary movements, but Topiramate was discontinued after one month due to side effects with depressive symptoms and fatigue in both.

\section{Neuropsychological testing}

Neuropsychological test results for four subjects are shown in Table 2. Verbal IQ was consistently lower than performance IQ in all. The index subject showed reduced working memory and attention in the PASAT test, scoring 29/60.

Subjects IV:1, IV:2 and IV:3 were tested with WISC-IV and all showed working memory and processing speed in the lower range. These three subjects performed in the lower normal range in verbal memory and verbal fluency, while visual memory and understanding was in the middle normal range.

All four reported concentration problems, as reflected in reduced attention and concentration. The most significant attention impairment was seen in patient IV:1, with Stroop results corresponding to the $2^{\text {nd }}$ percentile.

\section{Case description}

The index patient was referred to our clinic due to unsteadiness and clumsiness from early school age. She wanted a second opinion when she was 34 years old on her "hereditary ataxia" diagnosis.

The hyperkinetic movements started in infancy and her parents described her as a restless baby. When she was examined, at age 34 and at follow-up at age 36 , she had obvious hyperkinetic movements, most prominent in the trunk. She reported no obvious progression, but 


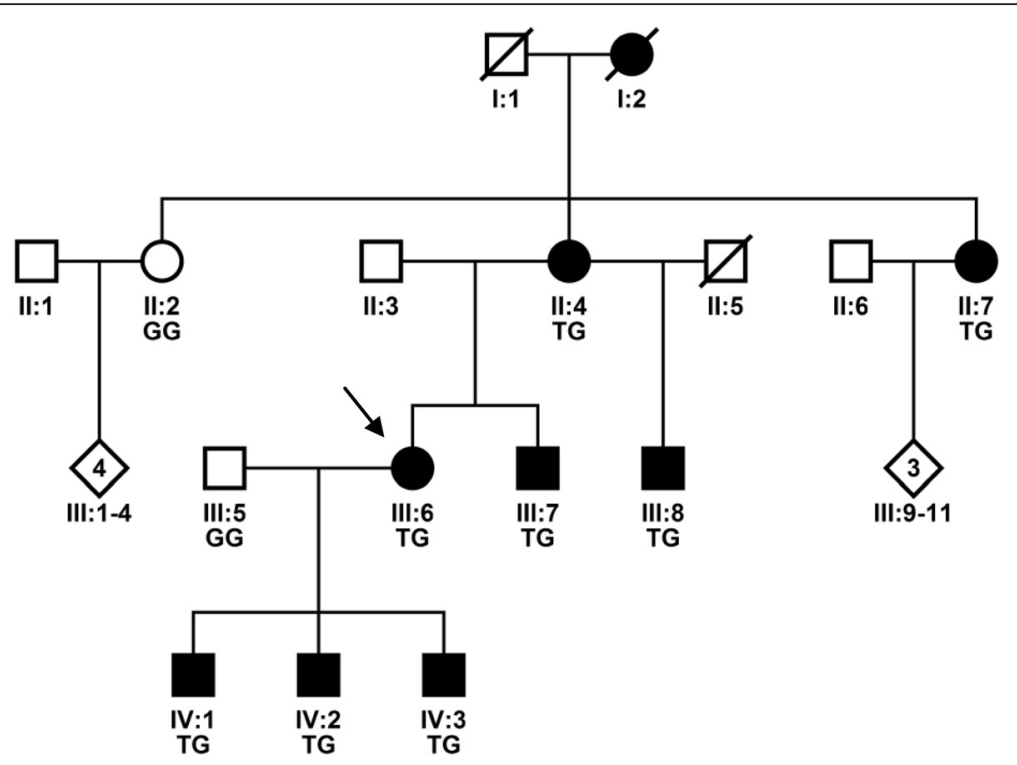

Fig. 2 The pedigree of the family

worsening in the involuntary movements during adolescence and pregnancy. She described her movements as a lack of ability to keep her body at rest. She experienced her first pneumonia at the age of 34 years and was diagnosed with asthma at the age of 36 years and for which she received medications.

The most noticeable findings at the first examination were myoclonic movements in the trunk, unsteadiness with abnormal gait and the inability to walk ten consecutive steps in tandem. She was, however, able to stand with her feet together. She had intermittent sway when sitting and subtle choreic movements were observed in her hands.
Her SARA score was 6/40 points, with unsteadiness and very mild ataxia in extremities. Her speech was normal.

After two years follow-up the examination was similar with the same SARA score (6/40 points).

Elevated levels of thyroid-stimulating hormone in serum $(\mathrm{TSH})$, with normal thyroxin $\left(\right.$ free $\mathrm{T}_{4}$ ) values were measured.

\section{Genetics}

All affected subjects carried a point mutation in exon 3, c.671 T > G, p.Leu224Arg, previously reported for this family [5]. Array CGH was normal in the index patient.

Table 2 Clinical data of the affected family members

\begin{tabular}{|c|c|c|c|c|c|c|c|c|}
\hline & SARA score & $\begin{array}{l}\text { Hyperkinetic } \\
\text { movements }^{a}\end{array}$ & Thyroidea & Lungs & MMS & IQ & $\begin{array}{l}\text { Verbal IQ } \\
\text { (percentile) }\end{array}$ & $\begin{array}{l}\text { Performance IQ } \\
\text { (percentile) }\end{array}$ \\
\hline$\|: 4$ & 12.5 & Dystonia & $\begin{array}{l}\text { Normal values, } \\
\text { treated earlier }\end{array}$ & Asthma & NA & NA & & \\
\hline$\|: 7$ & 10.5 & Dystonia, mild ataxia & $\begin{array}{l}\text { Hypothyreoses, } \\
\text { treated }\end{array}$ & Asthma & NA & NA & & \\
\hline III:6 & 6 & $\begin{array}{l}\text { Myoclonus, mild } \\
\text { ataxia }\end{array}$ & $\begin{array}{l}\text { Compensated } \\
\text { values }^{\mathrm{b}}\end{array}$ & Asthma & $30 / 30$ & 99 & 41th & 59th \\
\hline III:7 & 7 & Dystonia & $\begin{array}{l}\text { Compensated } \\
\text { values }^{b}\end{array}$ & $\begin{array}{l}\text { Frequent } \\
\text { infections }\end{array}$ & NA & NA & & \\
\hline |Il:8 & 5 & $\begin{array}{l}\text { Dystonia, stuttering, } \\
\text { tics, }\end{array}$ & Normal values & $\begin{array}{l}\text { No lung } \\
\text { problems }\end{array}$ & NA & NA & & \\
\hline IV:1 & 5.5 & & Normal values & Asthma & $0 / 30$ & 90 & 14th & 95th \\
\hline $\mathrm{N}: 2$ & 5 & & Normal values & Asthma & $30 / 30$ & 81 & NA & NA \\
\hline $\mathrm{N}: 3$ & 7 & & $\begin{array}{l}\text { Compensated } \\
\text { values }^{\mathrm{b}}\end{array}$ & Asthma & $30 / 30$ & 86 & 30th & 68th \\
\hline
\end{tabular}

${ }^{a}$ In addition to chorea

${ }^{\mathrm{b}}$ Normal fT4, but elevated TSH 


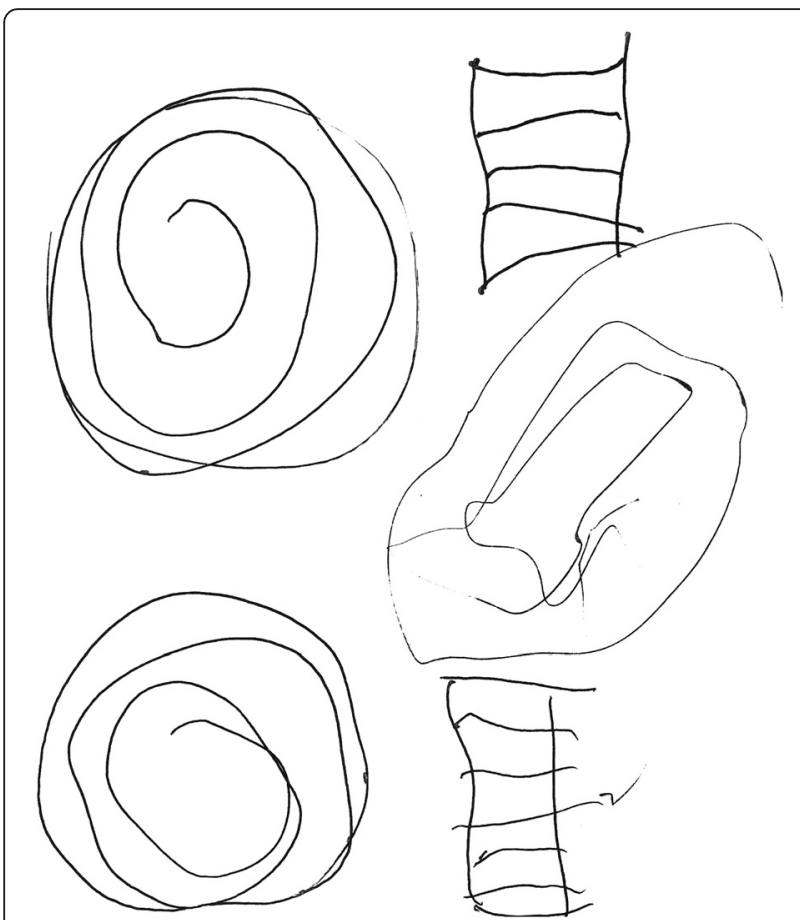

Fig. 3 A typical Archimedes spiral drawing by one of the affected subjects

\section{Conclusions}

This family presented a broad spectrum of hyperkinetic movements with chorea as the most prominent symptom in the youngest generation, but with combinations of dystonia, myoclonus, mild ataxia and stuttering in the older generations. At the time of examination, all affected subjects exhibited unsteadiness, and were unable to walk in consecutive tandem steps. The affected index family member was originally diagnosed with hereditary ataxia, due to family history and mild ataxia. The predominant feature, chorea, was probably overseen in this family and delayed the identification of the correct etiology. In addition neither progression nor atrophy of the cerebellum on MRI scans were observed in this family. The diagnosis was therefore revised. This emphasizes the importance of accurate phenomenology and the importance of examination of more family members due to intrafamiliar clinical heterogeneity, which is commonly seen in monogenetic disorders, Table 1 [30].

Even though myoclonus, dystonia or chorea have been reported in various genetic forms of hereditary ataxia, mutation screening of the NKX2-1 gene (BHC) should be made in cases of juvenile "ataxia" with no other cause found. There is a wide phenotypic heterogeneity in BHC families, in addition to frequent de novo mutations.

Conversely, BHC may share some clinical features with other hyperkinetic disorders, especially where a mixture of choreic movements, myoclonus and dystonia is concerned,
Table $1[6,9,11,18,31]$. An alternative diagnosis in this family may have been myoclonic dystonia (DYT11), as myoclonus and dystonia were additional movements in generation II and III. The lack of maternal imprinting in the pedigree and typical choreic movements in the youngest generation made however the diagnosis unlikely [8].

In this family a diagnosis of hereditary ataxia was less likely as the hyperkinetic feature chorea was the most prominent symptom and finding, even though all subjects were unsteady and two had mild ataxia. Hyperkinetic movements, autosomal dominant inheritance pattern, early onset, normal MRI scans and minimal progression made us therefore consider BHC [6]. A correct diagnosis is of great importance for the patients, especially as many differential diagnoses, including early onset ataxia, often have a more severe prognosis compared to BHC [30]. However, slight progression in children could be masked by overall improved motor skills and can therefore be difficult to assess.

The opposite may also be true as there are some families with BHC phenotypes that do not have NKX2-1 mutations. Some families have been reported to have ADCY5 mutations $[18,19]$. The main distinctive features that may help to differentiate the $A D C Y 5$ families from NKX2-1 families are facial myokimias, paroxysmal movement disorders, spasticity, more prominent dystonic features and clinical progression in the $A D C Y 5$ families reported.

All affected members of the family reported concentration problems and the neuropsychological domains attention, working memory and processing speed were indeed affected. The patients who were extensively cognitively tested were consistently better in executive and visuospatial functions as compared to verbal functions, with verbal IQ being consistently lower than executive performance IQ. Although previous reports on cognition in BHC have been conflicting, it has still not been established whether the impairment is a direct consequence of the different mutations, whether it is biased by the motor symptoms or as a consequence of hypothyroidism in some of the subjects. A drawback in this and previous reports is the low number of patients available for neuropsychological testing.

Even though a broad specter of cognitive profiles are reported in previous papers on BHC patients, the phenotype usually shows a mild cognitive decline and no alteration over time has been reported. Normal cognitive status is reported to be more likely in BHC compared to other chorea genotypes, and is considered to be a good clue to differentiate BHC from neurodegenerative forms of chorea [31-33]. Our observations suggest that, even when patients have some alterations in cognitive tests, they have completely different cognitive profiles compared to the hereditary neurodegenerative forms of chorea [6]. 
To date, the most successful treatments reported in a few individual patients with $\mathrm{BHC}$ are tetrabenazine and levodopa $[5,20,24]$. These medications were tested in some of the patients, but only side-effects and no or little benefit on the hyperkinetic movements was observed. Therefore no conclusions or guidelines can be drawn from this family or previous reports.

The best treatment options for most patients with BHC are probably still physical activity, physiotherapy, multidisciplinary facilitation at school and at work, and yearly lung and thyroid controls and treatment if needed.

In conclusion, although the neurological spectrum of $\mathrm{BHC}$ is more and more delineated, our family illustrates that hyperkinetic movement in addition to chorea can be prominent in these families. Therefore, we suggest considering BHC with mutations in the NKX2-1 gene in the diagnostic workup also in those patients with hyperkinetic movements such as early onset dystonia and ataxia.

\section{Consent}

Written informed consent was obtained from patients for publication of this Case report. A copy of the written consent is available for review by the Editor-in-Chief of this journal.

\section{Additional files}

Additional file 1: Video 1. Video 1 illustrates choreic movements in one of the patients. (MOV $6721 \mathrm{~kb}$ )

Additional file 2: Video 2. Video 2 illustrates chorea, dystonia and hanging patellar reflex in one of the patients. (MOV 9599 kb)

Additional file 3: Video 3. Video 3 illustrated mild ataxia when performing the heel-knee-shin test. (WMV 3646 kb)

\section{Abbreviations}

BHC: Benign hereditary chorea.

\section{Competing interests}

The authors declare that they have no competing interests.

\section{Authors' contributions}

JK examined all the patients, planned the study and wrote the manuscript. $\mathrm{SOL}$ examined patients, planned the study and drafted the manuscript. IW performed and analyzed the neuropsychological investigations, planned the study and drafted the manuscript. MV performed video analyses of the patients, contributed in the study design and helped drafting the manuscript. ML carried out the molecular analyses and drafted the manuscript. CMET conceived the study on hereditary ataxias, investigated patients, performed video analyses of the patients, and drafted the manuscript. All authors read and approved the final manuscript.

\section{Acknowledgements}

We thank the family and all subjects who were willing to participate in this study and Cecilia Simonsen with constructive comments on the manuscript. JK was funded by Vestre Viken Health Trust and the Norwegian Neurological Association, IMW by the Norwegian South-Eastern Regional Health Authority grants and SOL by the Medical Student Research program at the Faculty of Medicine, University of Oslo.
List disclosures of all authors

JK, SOL, IW, MV, ML, CMET have no conflict of interests to report in relation to the present manuscript.

\section{Author details}

${ }^{1}$ Department of Neurology, Drammen Hospital, Vestre Viken Health Trust, Drammen, Norway. ${ }^{2}$ Institute of Clinical Medicine, University of Oslo, Oslo, Norway. ${ }^{3}$ Department of Neurology, Oslo University Hospital, Ullevål, Oslo, Norway. ${ }^{4}$ Department of Neurology, Salpêtrière Hospital, APHP, Sorbonne Universités, UPMC Univ Paris 6 UMR S 1127, Inserm U 1127, CNRS UMR 7225, Institut du Cerveau et de la Moelle épinière, Paris, France. ${ }^{5}$ Laboratoire de Biochimie et Génétique Moléculaire, Hôpital Armand Trousseau- AP-HP, Paris, France.

Received: 9 October 2015 Accepted: 8 January 2016

Published online: 02 February 2016

\section{References}

1. Inzelberg R, Weinberger M, Gak E. Benign hereditary chorea: an update. Parkinsonism Relat Disord. 2011;17(5):301-7. doi:10.1016/j.parkreldis.2011.01.002.

2. Kleiner-Fisman G. Benign hereditary chorea. Handbook Clin Neurol. 2011; 100:199-212. doi:10.1016/B978-0-444-52014-2.00012-4.

3. Haerer AF, Currier RD, Jackson JF. Hereditary nonprogressive chorea of early onset. N Engl J Med. 1967;276(22):1220-4.

4. Harper PS. Benign hereditary chorea. Clinical and genetic aspects. Clin Genet. 1978:13(1):85-95.

5. Gras D, Jonard L, Roze E, Chantot-Bastaraud S, Koht J, Motte J, et al. Benign hereditary chorea: phenotype, prognosis, therapeutic outcome and long term follow-up in a large series with new mutations in the TITF1/NKX2-1 gene. J Neurol Neurosurg Psychiatry. 2012;83(10):956-62. doi:10.1136/jnnp-2012-302505.

6. Peall KJ, Kurian MA. Benign hereditary chorea: An update. Tremor and Other Hyperkinetic Movements. 2015;1(14). doi:10.7916/D8RJ4HM5.

7. Asmus F, Langseth A, Doherty E, Nestor T, Munz M, Gasser T, et al. "Jerky" dystonia in children: spectrum of phenotypes and genetic testing. Mov Disord. 2009;24(5):702-9. doi:10.1002/mds.22426.

8. Armstrong MJ, Shah BB, Chen R, Angel MJ, Lang AE. Expanding the phenomenology of benign hereditary chorea: evolution from chorea to myoclonus and dystonia. Mov Disord. 2011;26(12):2296-7. doi:10.1002/ mds.23822.

9. Balint B, Bhatia KP. Isolated and combined dystonia syndromes - an update on new genes and their phenotypes. Eur J Neurol. 2015;22(4): 610-7. doi:10.1111/ene.12650

10. McMichael G, Haan E, Gardner A, Yap TY, Thompson S, Ouvrier R, et al. NKX2-1 mutation in a family diagnosed with ataxic dyskinetic cerebral palsy. Eur J Med Genet. 2013;56(9):506-9. doi:10.1016/j.ejmg.2013.07.003.

11. Walker RH. Differential diagnosis of chorea. Curr Neurol Neurosci Reports. 2011:11(4):385-95. doi:10.1007/s11910-011-0202-2.

12. Kumar G, Dixon A. Benign hereditary chorea: a case report and brief review of inherited choreas. Pediatr Neurol. 2014;51(4):532-6. doi:10.1016/j.pediatrneurol. 2014.06.001.

13. Dale RC, Grattan-Smith P, Nicholson M, Peters GB. Microdeletions detected using chromosome microarray in children with suspected genetic movement disorders: a single-centre study. Dev Med Child Neurol. 2012; 54(7):618-23. doi:10.1111/j.1469-8749.2012.04287.x.

14. Teissier R, Guillot L, Carre A, Morandini M, Stuckens C, Ythier H, et al. Multiplex Ligation-dependent Probe Amplification improves the detection rate of NKX2. 1 mutations in patients affected by brain-lung-thyroid syndrome. Hormone Res Pediatrics. 2012:77(3):146-51. doi:10.1159/000337214.

15. Breedveld GJ, Percy AK, MacDonald ME, De Vries BBA, Yapijakis C, Dure LS et al. Clinical and genetic heterogeneity in benign hereditary chorea. Neurology. 2002;59(4):579-84.

16. Breedveld GJ, van Dongen JW, Danesino C, Guala A, Percy AK, Dure LS, et al. Mutations in TITF-1 are associated with benign hereditary chorea. Hum Mol Genet. 2002;11(8):971-9.

17. De Vries BBA, Arts WFM, Breedveld GJ, Hoogeboom JJM, Niermeijer MF, Heutink P. Benign hereditary chorea of early onset maps to chromosome 14q. Am J Hum Genet. 2000;66(1):136-42. doi:10.1086/302725.

18. Carapito R, Paul N, Untrau M, Le Gentil M, Ott L, Alsaleh G, et al. A de novo ADCY5 mutation causes early-onset autosomal dominant chorea and dystonia. Mov Disord. 2015;30(3):423-7. doi:10.1002/mds.26115. 
19. Mencacci NE, Erro R, Wiethoff S, Hersheson J, Ryten M, Balint B, et al. ADCY5 mutations are another cause of benign hereditary chorea. Neurology. 2015; 85(1):80-8. doi:10.1212/WNL.00000000000001720.

20. Asmus F, Horber V, Pohlenz J, Schwabe D, Zimprich A, Munz M, et al. A novel TITF-1 mutation causes benign hereditary chorea with response to levodopa. Neurology. 2005;64(11):1952-4. doi:10.1212/01.WNL.0000164000.75046.CC.

21. Devos D, Vuillaume I, de Becdelievre A, de Martinville B, Dhaenens CM, Cuvellier JC, et al. New syndromic form of benign hereditary chorea is associated with a deletion of TITF-1 and PAX-9 contiguous genes. Mov Disord. 2006;21(12):2237-40. doi:10.1002/mds.21135.

22. Kleiner-Fisman G, Rogaeva E, Halliday W, Houle S, Kawarai T, Sato C, et al. Benign hereditary chorea: Clinical, genetic, and pathological findings. Ann Neurol. 2003;54(2):244-7. doi:10.1002/ana.10637.

23. Kleiner-Fisman G, Lang AE. Benign hereditary chorea revisited: a journey to understanding. Mov Disord. 2007;22(16):2297-305. doi:10.1002/mds.21644. quiz 452.

24. Fons C, Rizzu P, Garcia-Cazorla A, Martorell L, Ormazabal A, Artuch R, et al. TITF-1 gene mutation in a case of sporadic non-progressive chorea. Response to levodopa treatment. Brain Dev. 2012;34(3):255-7. doi:10.1016/j.braindev.2011.04.007.

25. Erichsen AK, Koht J, Stray-Pedersen A, Abdelnoor M, Tallaksen CM. Prevalence of hereditary ataxia and spastic paraplegia in southeast Norway: a population-based study. Brain. 2009;132(Pt 6):1577-88. doi:10.1093/brain/awp056

26. Schmitz-Hübsch T, du Montcel ST, Baliko L, Berciano J, Boesch S, Giunti P, et al. Scale for the assessment and rating of ataxia: development of a new clinical scale. Neurology. 2006;66(11):1717-20.

27. Delis DC, Freeland J, Kramer JH, Kaplan E. Integrating clinical assessment with cognitive neuroscience: construct validation of the california verbal learning test. J Consult Clin Psychol. 1988;56(1):123-30.

28. Folstein MF, Folstein SE, McHugh PR. "Mini-mental state". A practical method for grading the cognitive state of patients for the clinician. J Psychiatr Res. 1975;12(3):189-98.

29. Strauss E, Sherman EMS, Spreen O. A compendium of neuropsychological tests: administration, norms, and commentary. 3.Edition ed. New York: Oxford University Press; 2006.

30. Bird T. Hereditary ataxia overview. In: Bookshelf N, editor. Genereviews. 2015th ed. Bethesda, MD: GeneReviews; 2015.

31. Santens P, Van Damme T, Steyaert W, Willaert A, Sablonniere B, De Paepe $A$, et al. RNF216 mutations as a novel cause of autosomal recessive Huntington-like disorder. Neurology. 2015;84(17):1760-6. doi:10.1212/WNL.00000000000001521.

32. Cardoso F. Differential diagnosis of Huntington's disease: what the clinician should know. Neurodegenerative Dis Manage. 2014;4(1):67-72. doi:10.2217/nmt.13.78.

33. Zhu D, Burke C, Leslie A, Nicholson GA. Friedreich's ataxia with chorea and myoclonus caused by a compound heterozygosity for a novel deletion and the trinucleotide GAA expansion. Mov Disord. 2002:17(3):585-9. doi:10.1002/mds.10175

\section{Submit your next manuscript to BioMed Central and we will help you at every step:}

- We accept pre-submission inquiries

- Our selector tool helps you to find the most relevant journal

- We provide round the clock customer support

- Convenient online submission

- Thorough peer review

- Inclusion in PubMed and all major indexing services

- Maximum visibility for your research

Submit your manuscript at www.biomedcentral.com/submit

) Biomed Central 